\title{
PROJETO POLÍTICO-PEDAGÓGICO (PPP) E ROTATIVIDADE DOCENTE: DESAFIOS NA ATUAÇÃO DAS ESCOLAS FAMÍLIAS AGRÍCOLAS (EFAs) NO PIAUÍ
}

\author{
Political-Pedagogical Project (PPP) and teaching rotativity: challenges in the \\ performance of Agricultural Family Schools (EFAs) in Piauí
}

Lucineide Barros Medeiros ${ }^{1}$

Tânia Karinny Pereira Pires ${ }^{2}$

\begin{abstract}
RESUMO: No artigo, analisamos a relação entre as orientações do Projeto Politico-Pedagógico (PPP) de uma Escola Família Agrícola (EFA) do Piauí e o modo como se realiza a formação de seu quadro docente, em diálogo com princípios fundacionais da Educação do Campo e da Educação por Alternância, considerando marcadores históricos da exclusão escolar dos setores populares do campo e desafios existentes nos marcos normativos e na construção da política pública, que impõem a adoção de medidas que embargam a realização de propostas identificadas com os objetivos de transformação social. Utilizamos dados de entrevista e pesquisa documental, em dialogo com autores, como: Nosella (1997), Freire (2005), Caldart (2000), Santos (1997), dentre outros.
\end{abstract}

Palavras-chave: Escola Família Agrícola (EFA). Projeto Politico-Pedagógico (PPP). Quadro Docente.

ABSTRACT: In this paper, aims at analyzing the relationship between the Political-Pedagogical Project (PPP) and an Agricultural Family School (AFS) of the Piaui and the way in which the formation of its teaching staff takes place, dialoguing with foundation principles of Rural Education and of the alternance education, considering historical markers of the school exclusion of rural popular sectors and challenges current in the normative frameworks and politic policies construction, that impose measurement adoptions, frustrating the realization of identified planes with social transformation intentions. Interviews data and documentary research were used, dialoguing with authors like: Nosella (1997), Freire (2005), Caldart (2000), Santos (1997), among others.

Keywords: Agricultural Family School (AFS). Political-Pedagogical Project (PPP). Teaching Staff.

\section{CONSIDERAÇÕES INICIAIS}

O Projeto Político-Pedagógico (PPP) em uma escola representa o eixo de sustentação dos objetivos e das práticas realizadas, com vistas na formação. Expressam um conjunto de fatores internos e externos que, em convergência, no movimento do cotidiano possibilitam resultados mais

\footnotetext{
1 Doutora em Educação pela Universidade do Vale do Rio dos Sinos (UNISINOS). Professora da Universidade Estadual do Piauí (UESPI). Integrante do Núcleo de Estudos em Educação Popular e Educação do Campo (EPEC/UESPI).E-mail: lucineidebarrosmedeiros@yahoo.com.br

${ }^{2}$ Graduada em Pedagogia pela Universidade Estadual do Piauí (UESPI). E-mail: taniakarinny@outlook.com
} 
ou menos satisfatórios. Dentre esses, se encontram os que compõem o objetivo geral apresentado ao diálogo neste texto, que é analisar fatores relacionados à dinâmica de formação do quadro de docentes de uma Escola Família Agrícola (EFA) do Piauí e suas implicações na implementação da proposta pedagógica. De modo específico, pretendemos destacar procedimentos adotados para a composição do quadro de docentes da EFA Soinho e situar os mesmos no contexto geral das diretrizes e dos princípios das propostas pedagógicas da Educação do Campo e da Pedagogia da Alternância.

Os dados foram produzidos em pesquisa de campo ${ }^{3}$, de abordagem qualitativa, focando os porquês e possíveis explicações existentes no fenômeno em estudo (GERHART; SILVEIRA, 2009; RUIZ, 2008; PRADONOV; FREITAS, 2013) e no processo histórico de construção da Educação do Campo. As entrevistas, a um educador (G1) que integra a gestão da escola e outro (E2) que atua como monitor, juntamente com a análise documental, foram realizadas no ano de 2019, considerando as orientações e os procedimentos indicados, especialmente por Minayo (2001), Marconi; Lakatos (2011) e Triviños (2008). A construção analítica parte do movimento do real, materializado em relações que envolvem a EFA Soinho e a Secretaria de Estado da Educação do Piauí (SEDUC/PI), a partir da qual se viabiliza o quadro de docentes da escola, em diálogo com outro movimento, do ideal, presente nos princípios e orientações fundacionais da Educação do Campo, das EFAs e da Pedagogia da Alternância que, por sua vez, são marcados por tensões e contradições que revelam o fenômeno em foco nessa discussão.

Inicialmente apresenta-se uma consideração a respeito das ideias orientadoras das propostas político-pedagógicas da Educação do Campo e das EFAs, com destaque para a prática da Pedagogia da Alternância. Em seguida, uma breve caracterização da EFA Soinho, destacando o modo como é feita a composição do quadro docente da escola. A partir daí, pontuamos preocupações e problemas relacionados à política de contração de professores e repercussões nos objetivos e práticas escolares, em sintonia com desafios da Educação do Campo, da Pedagogia da Alternância e da realidade brasileira.

\section{ORIENTAÇÕES POLÍTICO-PEDAGÓGICAS PARA A EDUCAÇÃO EM ESCOLAS DO CAMPO}

No processo histórico brasileiro, identificamos a permanência de grave exclusão educacional dos povos não-urbanos e as bases de construção da Educação do Campo têm essa

\footnotetext{
${ }^{3}$ Esse texto foi elaborado em diálogo com uma pesquisa realizada nos marcos do Programa Institucional de Bolsas de Iniciação Científica (PIBIC) da Universidade Estadual do Piauí (UESPI), com apoio do Conselho Nacional de Desenvolvimento Cientifico e Tecnológico (CNPq).
} 
realidade como ponto de partida. São constituídas em meio aos esforços de construção de práticas educacionais e escolares orientadas por princípios da libertação, como as primeiras experiências do Movimento de Educação Promocional do Espírito Santo (MEPES) nos anos 1960, orientadas pelos aprendizados das escolas-família rurais da Itália, que originaram as bases para os projetos pedagógicos das Escolas Famílias Agricolas (EFAs) no Brasil (NOSELLA, 1977); as práticas das escolas sindicais, dos anos 1980 e 1990, promovidas especialmente pela Central Única dos Trabalhadores (CUT) (MANFREDI, 1986; CUT, 2000), vinculando organização, educação e trabalho; os ensinamentos de Paulo Freire que, com sua Pedagogia do Oprimido, sedimentou as bases da Educação Popular (BEISIEGEL, 1974; FREIRE, 2005) e, de modo destacado, nas primeiras experiências do Movimento dos Trabalhadores Rurais Sem Terra (MST), com sua “pedagogia do movimento" (CALDART, 2000).

O que atualmente conhecemos como Educação do Campo, em termos de Projeto Político-Pedagógico (PPP), reúne inspirações e contribuições de construções a exemplo das citadas acima, e está em permanente movimento, que tensiona suas bases fundacionais, fazendo com que seja cada vez mais difícil apreendê-la como fenômeno histórico. Contudo, é possível empreender esforços de sínteses dialéticas na articulação entre os seus princípios originários e as experiências vivenciadas, de intensa repercussão na vida dos(as) camponeses(as), em que pese o alcance limitado, diante dos vastos desafios a serem superados.

Partindo dessa compreensão e com o intuito de situar o PPP da EFA Soinho no contexto mais amplo da Educação do Campo, destacamos que, no Caderno 2 da coleção "Por uma Educação do Campo"4 (ARROYO; FERNANDES, 1999), há um conjunto de elementos que apresentam a relação indissociável da Educação do Campo com os movimentos sociais, por meio de gestos, da perspectiva do direito, da relação com a terra, do saber, da cultura e da luta pela escola.

No Caderno 4 são apresentados os "traços de uma identidade em construção" (KOLLING; CERIOLI; CALDART, 2004), na perspectiva de orientar ações diversas e, principalmente, em torno da construção de uma política pública de Educação do Campo, como dever do Estado: representa uma luta pelo direito de todos à educação; afirma que os sujeitos da Educação do Campo são os sujeitos do campo; se faz vinculada às lutas sociais do campo; no diálogo entre seus diferentes sujeitos; identifica a construção de um projeto educativo; inclui a construção de escolas do campo; nela, as educadoras e os educadores são sujeitos da Educação do Campo.

\footnotetext{
${ }^{4} \mathrm{Na}$ apresentação do Caderno 1 está escrito que a coleção de cadernos se deu a partir de um dos compromissos assumidos na "I conferência Nacional: Por uma Educação Básica do Campo", com a finalidade de alimentar a reflexão, motivar a mobilização das bases e favorecer o intercâmbio de experiências.
} 
Esse último traço, indica desafios à educadores e educadoras do campo, destacados no mesmo Caderno 4: "necessidade permanente de nos capacitar, de estudar sempre e muito"; "não basta apenas ficarmos mais 'sabidos', mais cultos, conhecedores dos problemas do campo, da agricultura e da educação. É preciso se desafiar a transformar o conhecimento em ação"; "transformar ação em conhecimento"; "consolidar um espaço permanente de debate, de reflexão sobre o que estamos fazendo e sobre o que acontece no campo, ao nosso redor e em nosso país"; “fortalecer a Educação do Campo como área própria de conhecimento”; "fortalecer a Educação do Campo também nos espaços públicos, nos sistemas de ensino, tanto municipais, quanto estaduais"; "contribuir na construção de um novo modelo de desenvolvimento [...], nos inserir nos debates públicos sobre educação escolar"; "contribuir para a reinserção do campo na agenda de pesquisa"; constituição de "coletivos pedagógicos na nossa área de atuação"; realizar "encontros promovidos pelas articulações regionais e estaduais [...] dialogando sobre suas praticas”.

A “I Conferência Nacional: Por uma Educação Básica do Campo", realizada nos dias 27 a 30 de julho de 1998, foi um dos passos seguintes ao I Encontro Nacional de Educadores da Reforma Agrária (I ENERA), promovido pelo Movimento dos Trabalhadores Rurais Sem Terra (MST). A Conferência reuniu esforços de pessoas vinculadas à instituições e de entidades que atuavam no mundo rural, a exemplo da Conferência Nacional dos Bispos do Brasil (CNBB), com seus organismos e incidência nas experiências de EFAs, conforme está registrado no Caderno 1 (KOLLING; NERY; MOLINA, 1999).

De acordo com Arroyo (1999), naquela conjunção de esforços, havia a retomadas de matrizes da tradição pedagógica, bem como, de aprendizados das experiências, nas quais podemos situar a contribuição das EFAs.

Gimonet (2007) nos apresenta os princípios orientadores das EFAs: a) primazia da experiência sobre o programa; b) articulação dos tempos e dos espaços da formação; c) um processo de alternância em ritmo em três tempos: familiar, escolar e meio social; d) associação da formação profissional e da formação geral; e) cooperação, ação e autonomia; f) a associação dos pais e mestres de estágios profissionais como parceiros e co-formadores.

Ressalta também, a importância da articulação entre os momentos das atividades do meio sócio-educacional em que vivem os educandos e educandas com os momentos escolares (GIMONET, 1999). Nesse sentido, entendemos que é necessário organizar e conduzir um processo intencionalm que viabilize pedagogicamente a unidade dessas dimensões; construção que exige uma equipe pedagógica em fina sintonia com os princípios e os objetivos.

$\mathrm{Na}$ dinâmica das EFAs, há o desafio que esse trânsito e a produção que dele decorre se constitua como uma pedagogia, a Pedagogia da Alternância que, de acordo com Gimonet (1999, 
p. 26), "dá prioridade a experiência familiar, social, profissional, ao mesmo tempo como fonte de conhecimento, ponto de partida e de chegada do processo de aprendizagem, e como caminho educativo".

Jesus (2011) sistematizou uma lista de Instrumentos Pedagógicos que compõem a Pedagogia da Alternância: Plano de estudos, Colocação em Comum, Caderno de Realidade, Viagem e visita de estudos, Estágio, Serões, Visitas às Famílias, Caderno de Acompanhamento, Tutorial, Projeto Profissional do Jovem, Atividade de Retorno e Avaliação.

O Plano de Estudo é onde se busca articular os conhecimentos construídos em sala de aula com os saberes trazidos das vivências e experiências na comunidade e no seio familiar (CERQUEIRA; SANTOS, 2010). As questões suscitadas nesse Plano são socializadas e sistematizadas nas Colocações em Comum. Jesus (2011, p. 86) ressalta que por meio do Caderno de Acompanhamento, "é possível dialogar entre as aprendizagens construídas nesses dois espaços tempos: família e a escola" e assim, os processos se desenvolvem integrando os diferentes instrumentos em tempos e espaços.

De acordo com Lima; Sousa; Melo (2018, p. 34), estes representam "mediações se propõem a materializar os princípios que sustentam essa pedagogia, como proposta de rupturas com sistemas fundamentados em paradigmas tradicionais liberais tecnicistas". Além disso, citam Begnami (2004, p. 49) ao afirmar que o(a) professor(a) na EFA é aquele(a) que "orienta, motiva, aguça curiosidades, provoca, problematiza, ajuda a construir ou reconstruir conhecimentos, facilita aprendizagens e quando necessário também, ensina”.

Esse esforço, que reúne lutas dos movimentos sociais e intenso trabalho intelectual fez com que a proposta pedagógica de formação pela alternância chegasse a integrar a política educacional do país, como se pode observar no "Caderno de Instruções do Censo Escolar" de 2018, no qual está escrito que:

O projeto político-pedagógico da escola contempla os princípios da alternância formativa, isto é, alterna períodos de aprendizagem na família, em seu próprio meio, com os de aprendizagem na escola. Esses tempos estão interligados por instrumentos pedagógicos específicos, pela associação, de forma harmoniosa, entre família e comunidade e por uma ação pedagógica que visa à formação, inclusive para prosseguimento de estudos, e contribui positivamente para o desenvolvimento rural integrado e autossustentável, particularmente naquelas regiões/localidades em que prevalece a agricultura familiar. (BRASIL, 2018, p. 47)

Diante dos desafios dessa proposta, compreendemos que a realização de um PPP escolar baseado na Pedagogia da Alternância exige, para a sua realização, um coletivo de professores e professoras com condições objetivas e subjetivas específicas. Nesse sentido, passamos a refletir 
sobre a questão, a partir da realidade particular da EFA Soinho, levando em consideração, principalmente, o modo como se define o seu quadro de docentes. Vale reiterar que os dados apresentados a seguir foram produzidos por meio de pesquisa de campo e análise documental, no ano de 2019.

\section{EFA SOINHO E PEDAGOGIA DA ALTERNÂNCIA}

A Escola Família Agrícola do Soinho está localizada na Estrada da Cacimba Velha S/N, Povoado Soinho, Município de Teresina (PI), na região denominada Grande Socopo. Trata-se de uma escola vinculada à Fundação Padre Antônio Dante Civiero (FUNACI), sem fins lucrativos, criada em 1989, com natureza jurídica de fundação, inspirada nos princípios da Doutrina Social da Igreja Católica, para desenvolver ações nos setores da saúde, educação, assistência social e agricultura.

As EFAs vinculadas à FUNACI compõe a Associação das Escolas Famílias Agrícolas do Piauí (AEFAPI) e, diante de problemas estruturais e financeiros para manter as escolas somente com o apoio das famílias, estabeleceram uma relação com a Secretaria de Educação, em que esta passa a fornecer a quase totalidade de seus(as) professores(as) e os estudantes são contabilizados no universo de alunos(as) da rede pública do Piaú.

À época da pesquisa a instituição atendia, em maior número, estudantes do município de Teresina, mas também, de outras localidades do Piauí e, até de outros estados. Trata-se de uma escola habilitada em Educação Profissional Técnica em Agropecuária Integrada ao Ensino Médio. O curso se realizava em carga horária de 4.800 horas-aula, sendo 300 de estágio. No segundo semestre do ano de 2019, contava com 26 estudantes na $1^{\circ}$ Ano; 19 estudantes no $2^{\circ}$ Ano e 24 estudantes no $3^{\circ}$ Ano. 22 funcionários no total, sendo 01 diretor, 01 coordenador pedagógico, 04 vigias, 01 cozinheira, 01 bibliotecária, 02 tutores noturnos e 12 professores(as). As sessões escolares e familiares duram 15 dias, cada uma.

A escola ocupava uma área de 30 hectares, com instalações da parte administrativa formada pelas dependências da diretoria, coordenação pedagógica e secretaria escolar, mecanografia, salas de professores, 02 salas de aula, laboratório de ciências (Física e Biologia), biblioteca, área (coberta) de convivência, refeitório, sala de leitura, almoxarifado, 02 oficinas, 01 mini-fábrica de ração para suínos e frangos, 01 pocilga e 01 campo de futebol. Havia o cultivo de manga, citrus e acerola. Contava com o auxílio da Fazenda Nova Esperança, propriedade pertencente à FUNACI, que embora com equipamentos e instalações precárias, dava suporte para a realização de práticas e estágios. 
Essa estrutura se movimenta com base em ações pedagógicas. Um educador da escola informou em entrevista que no inicio de cada sessão "é realizado um planejamento pedagógico com os professores. São planejadas as aulas de campo, os eventos, as atividades externas, as intervenções [...]" (E2, entrevista, 2019)

De acordo com a Lei de Diretrizes e Bases da Educação Nacional (LDB 9.394/96) e as diretrizes operacionais para a educação nas escolas do campo (resoluções CNE/CEB, nº 01/2002 e n $n^{\circ}$ 2/2008), a organização das ações pedagógicas na escola do campo deve considerar e adequarse às singularidades da vida no campo. Os conteúdos curriculares e as metodologias devem ser apropriados às necessidades e os interesses dos(as) estudantes da zona rural. A organização escolar interna e seu calendário devem estar de acordo com as fases do ciclo agrícola e as condições climáticas, respeitando a adequando-se à natureza do trabalho na zona rural.

Esse movimento pela alternância que envolve diferentes tempos, espaços e atividades, precisa ser guiado por intencionalidades pedagógicas produzidas pela sua equipe pedagógica, onde a participação dos professores e professoras é indispensável. Antes de seguir, é necessário ressaltar que na dinâmica de organização da EFA, professores e professoras recebem a denominação de monitores e monitoras, conforme explicam Lima; Sousa; Melo (2018, p. 116), acrescentando que "Os monitores atuantes nas EFAs possuem funções e responsabilidades diferenciadas dos professores das escolas convencionais".

Assim, a atuação de professores e professoras na EFA, considerando sua estrutura física, seus tempos, seus espaços e a orientação geral da Pedagogia da Alternância, requer formação específica, jornada e condições de trabalho diferenciada e, consequentemente, remuneração que corresponda às demandas desse conjunto. Falando a respeito disso, um educador da EFA Soinho informou em entrevista que: "existem encontros periódicos quinzenais da equipe de educadores, os encontros com os educandos, os encontros com as famílias, e de tudo isso são tirados elementos de composição do planejamento." (G1, em entrevista, 2019).

Esse movimento pode vincular a equipe pedagógica não somente às famílias e aos territórios em que vivem os(as) estudantes, mas também, às lutas estruturais fundamentais à construção da Educação do Campo, como a luta pela Reforma Agrária. Tudo isso, em vista de que o trabalho docente não se encerra com a diplomação, esses vínculos trazem à pauta de atuação dos educadores e educadoras as tensões e às necessidades do meio rural e do mundo do trabalho no campo, como terra, crédito e outras políticas necessárias para assegurar a permanência. Por essa via é possível pensar em um processo de afirmação dos educadores e educadoras da escola do campo como sujeitos do campo, sem, necessariamente, viverem no meio rural. 
É com base nessa compreensão, que Jesus (2006, p. 64) considera a EFA “um instrumento importante no processo de formação para o desenvolvimento do campo, por ter surgido da luta pela reforma agrária e pela posse da terra" e, pela perspectiva dessa discussão, podemos afirmar que a EFA Soinho, representa uma alternativa concreta à exclusão educacional e sócio-política do campo e, nesse contexto, também seus educadores e educadoras, porque carregam em si, a potência de contribuir com a alteração positiva da realidade rural, com a qual podem formar uma unidade dialética. Contudo, cabe ressaltar: essa potência apresentada em seu PPP depende, para materializar-se, de um conjunto de fatores, a exemplo dos que serão destacados a seguir.

\section{PROCESSO DE “ESCOLHA” DO QUADRO DE DOCENTES DA EFA SOINHO}

A maioria das EFAS do Piauí vive uma situação diferenciada, do ponto de vista da composição de seu quadro de docentes, pois não é comum encontrar um tipo de relação direta entre EFA e órgão oficial de educação nos estados em que estão outras experiências. Na EFA Soinho, conforme informado anteriormente, a maior parte do quadro de professores(as) pertence e é fornecida pela SEDUC/PI.

À época da pesquisa, o método de contratação se realizava conforme o estabelecido em editais simplificados, e a duração dos contratos era de até um ano, em conformidade com o que está estabelecido no Artigo $4^{\circ}$, inciso III da Lei no ${ }^{\circ}$ 8.745/1993, citada nos Editais SEDUC/PI ${ }^{\circ}$ 05/20175 e no 01/2015 ${ }^{6}$, e no Decreto Estadual do Piaú, no 15.547/2014.

A Lei nº 8.745/1993, mencionada acima, "dispõe sobre a contratação por tempo determinado para atender à necessidade temporária de excepcional interesse público [...]”. No caso das EFAs, conforme consta nos princípios orientadores de sua pedagogia e dinâmica de trabalho, não se apresenta como uma atividade temporária, ao contrário, trata-se de um processo permanente e continuado, com sessões escolares e familiares, ambas exigentes de acompanhamento dos professores e professoras, equipes técnicas e das equipes pedagógicas em seu todo, para que o processo possa fluir sem interrupções, acumulando as construções das etapas alternadas.

Lidar de modo articulado com esse conjunto exige exercício de sistematização, reflexão coletiva, compartilhamento de tarefas, para além das aulas que convencionalmente conhecemos. Exige a orientação e o acompanhamento à realização de cada instrumento pedagógico e de todos

\footnotetext{
${ }^{5}$ Disponível em: < https://nucepe.uespi.br/downloads/edital_seduc2017.pdf >. Acesso em: 20 abr. 2020.

${ }^{6}$ Disponível em: < http://www.cge.pi.gov.br/legis/legislacao/decreto-estadual-15.547-2014-regulamenta-a-lei-5.3092013-contratacao-por-tempo-determinado.pdf >. Acesso em: 20 abr. 2020.
} 
em conjunto, acompanhamento à dinâmica de convivência no internato, com as tensões próprias de ambientes juvenis, tudo isso, em duas dimensões de espaço e de tempo, na escola e na família.

Para que cada passo desse processo se realize como soma para a realização do objetivo geral é necessário que haja uma construção em rede, baseada na socialização, na avaliação e no (re)planejamento permanente, a exemplo do que feito, conforme a fala de G1. É necessário que sejam construídos laços de comunicação, solidariedade e partilha, que permita acúmulo, como processo de totalização, onde cada parte é necessária e deve se fazer presente com suas singularidades.

Paulo Freire (1983) é uma das vozes de destaque na defesa do coletivo de professores e professoras como um sujeito coletivo, agindo no processo, porém, ressalta que este não deve suplantar o protagonismo individual, sem o qual não se processa o trabalho coletivo, pois a condição de inacabamento dos seres humanos, exige que o coletivo se realize em relações de subjetivação que levam à objetivações que se fazem em processos de diálogo.

Esse processo também é formador dos educadores e educadoras, pois nele se torna possível a consciência do eu, que para realizar-se exige relação com o não eu, onde nossos companheiros(as) de trabalho, com com seus modos diferentes de ser e fazer vão nos conduzindo à implicações mais profundas, nem sempre tranquilas, das quais não tomaríamos consciência vivendo apenas em nossas esferas de mundo, distanciados(as) das diferenças.

Freire (1983, p. 44) explica que "a separação do contexto total em suas partes nos permite retomar a ele, de onde partimos, pelo ad-mirar, alcançando, desta maneira, uma compreensão mais vertical e também dinâmica de sua significação".

Como viabilizar esse tipo de construção tão complexa, que integra a proposta pedagógica da Educação do Campo e da EFA, com grupos de professores e professoras que se renovam a cada ano, que sequer conseguem construir afinidades, testar possibilidades, reconhecerem-se como parte de um grupo maior? Como viabilizar um trabalho tão exigente de tempo e de condições materiais especificas, submetidos(as) ao regime de trabalho comum aos(às) demais professores e professoras da rede?

Identificamos que a contração de professores e professoras para as EFAs, via contratos temporários, pode se justificar nas necessidades e nas medidas operacionais da SEDUC/PI, mas não se justifica nas necessidade das EFAs, e tampouco nos marcos legais. O Artigo $2^{\circ}$ da Lei $n^{\circ}$. 8.745/1993, apresenta os seis casos que justificam a contratação temporária excepcional: I assistência a situações de calamidade pública; II - combate a surtos endêmicos; III - realização de recenseamentos; IV - admissão de professor substituto e professor visitante; V - admissão de 
professor e pesquisador visitante estrangeiro; VI - atividades especiais nas organizações das Forças Armadas para atender a área industrial ou a encargos temporários de obras e serviços de engenharia.

Se considerarmos que o inciso IV indica a situação geradora da contração para as EFAs, e que a condição de professor e professora substituto(a) é gerada no fato de existir na vaga a ser preenchida um(a) professor(a) efetivo(a) que, por razões reguladas em lei, pode pedir afastamento, ocasionando a necessidade de contratação temporária de outro(a), podemos afirmar que essa não é a alternativa a ser aplicada na seleção de professores e professoras para as EFAs, posto que, até o momento, não foram criadas vagas para professores e professoras efetivos(as), em sistema de alternância, na rede pública estadual do Piauí, ou seja, os(as) contatados(as) temporariamente não estão substituindo ninguém, mas ocupando um espaço que ainda não foi corretamente tratado no contexto da política pública.

Pela análise de dois editais de seleção, o n $01 / 2015$ e o n ${ }^{\circ}$ 05/2017, identificamos que no primeiro a seleção ocorreu em única fase, compreendendo a Análise de Currículo, de caráter eliminatório e classificatório. No segundo, igualmente, em fase única, porém, com Prova Escrita Objetiva, também de caráter eliminatório e classificatório.

No item sobre as exigências para a contratação, o Edital no 01/2015 não apresentou critérios objetivos relacionados ao tipo de trabalho a ser realizado nas EFAs. Trouxe apenas, um quadro de itens e pontos para referenciar a análise do currículo, com três componentes centrais: formação acadêmica; experiência profissional e atividades complementares. Em nenhuma das alternativas apresentadas há menção à especificidade da Educação do Campo, à Alternância, ou a algo que se aproxime desses referenciais. No Edital 05/2017, o conteúdo programático apresentado para a prova escrita foi Língua Portuguesa e Legislação Específica da Educação Profissional ou Especial.

Vale salientar que, nenhum dos dois editais foi específico para a seleção de professores e professoras de EFAs, tanto o de 2015, como o de 2017, selecionaram "Professores das disciplinas específicas dos cursos de Educação Profissional Técnica de Nível Médio ofertados nos Centros Estaduais de Educação Profissional e Escolas Família Agrícola - EFA'S” e também para "cargos de Técnico de Nível Médio e Nível Superior" e para "Instrutor e Intérprete de LIBRAS para os Centros de Atendimento Educacional Especializado". Nesse sentido, são editais com elaborações muito aproximadas aos demais, apresentados pela Secretaria, para seleção de professores e professoras temporários(as) com formação acadêmica equivalente e não consideram o que a especificidade das EFAs pede ao processo de formação e de atuação de seu quadro docente. Não somente por não observar afinidades iniciais $\operatorname{dos}($ as) candidatos(as) com a temática das provas e(ou) por não ter experiência, porque isto pode ser construindo, e a EFA se dispõe a contribuir com a 
construção, como informa a fala do educador: "necessita os educadores estarem em processo permanente de formação, então nós fazemos formação em módulos processuais que chegam a ter uma carga horária até maior do que é exigido nas especializações." (G1, em entrevista, 2019).

Vale ressaltar que esse tipo de contrato para o quadro provisório não inclui estágio probatório, momento em que há, em tese, a preparação para o trabalho, bem como, a avaliação das condições objetivas e subjetivas do(a) profissional para a função.

\section{PROJETO POLÍTICO-PEDAGÓGICO (PPP) E ATUAÇÃO DOCENTE FRENTE À DÍVIDAS HISTÓRICAS}

Inferimos que o tipo de seleção apresentado abre um leque de problemas na condução do PPP das EFAs. Essa afirmação não desconsidera a atenção que deve ser dada aos princípios legais e normativos que regem a seleção por concurso publico, especialmente no tocante à acessibilidade e a igualdade de condições, para evitar favoritismo.

Contudo, é, ao mesmo tempo, necessário ressaltar que a marca da exclusão histórica impressa na realidade brasileira, tem provocado lutas e alterações nos referenciais sobre igualdade, exemplo da que se encontra na base de construção da Educação do Campo. Boaventura de Sousa Santos (1997, p. 97) nos chama a pensar sobre algo que ele apresenta como um imperativo: "as pessoas e os grupos sociais têm o direito a ser iguais quando a diferença os inferioriza, e o direito a ser diferentes quando a igualdade os descaracteriza". Por esse referencial, precisamos assumir a conquista da reserva de vagas e o reconhecimento das necessidades especiais nas regras de concursos, como tensões importantes, frente à ideia de ter a igualdade como um critério absoluto, afastado do principio ético e da justiça social.

A AEFAPI tem afirmado publicamente que defende seleções de professores e professoras para as EFAs baseadas em editais próprios e específico, elaborado com a participação das escolas e organizações vinculadas à Educação do Campo, incluindo itens que permitam articular critérios de seleção dos(as) candidatos(as) à natureza do trabalho que irão assumir: "nossa luta junto ao estado é de que nossos educadores sejam selecionados a partir de uma proposta de um edital que considere o currículo porque nós entendemos que a nossa metodologia é baseada numa dinâmica de trabalho do ver, julgar e agir, a ação-reflexãoação [...]” (G1, entrevista, 2019).

Esse apelo encontra justificativa também, na existência de egressos de cursos de graduação e pós-graduação em Educação do Campo, promovidos pelas Instituições de Ensino superior (IES) do Piauí, em tese, com melhores condições de conhecimento para atuar nas EFAs, sem desconsiderar que o conhecimento prévio, em si, é insuficiente. Porém, soma-se a isso, o fato 
de a Educação do Campo ser uma das modalidades de ensino, em meio a outras, instituídas no sistema educacional brasileiro, que carrega especificidades que o escopo geral das matrizes curriculares de formação de docentes na atualidade não consegue alcançar: Educação de Jovens e Adultos (EJA), Educação Especial, Educação Profissional e Tecnológica; Educação indígena e Educação Quilombola, Educação à Distância.

Quase todas funcionam também como política de ação afirmativa. No caso da Educação do Campo, para suprir necessidades históricas formadas na exclusão territorial e dos setores populares do meio rural; para favorecer acesso e permanência na escola, em condições adequadas às suas realidades, conforme estabelece o seu marco legal.

Assim, entendemos que esse conjunto de modalidades representa conquistas recentes e exigem um esforço diferenciado voltado à formação de docentes em condições adequadas de atuação. Certamente, trata-se de uma construção complexa, tendo em vista, as questões que atravessam as licenciaturas, em relação aos conteúdos, tempo de formação, papeis da formação inicial e da formação continuada. Porém, não é possível desconhecer que cada vez mais o campo de atuação do(a) docente ganha amplitude e singularidades, cada vez mais, as agências de formação cedem aos apelos de aligeiramento que orientam a política de formação e, diante disso, ficam os desafios de não perder de vista que não será possível superar as desigualdades sem tratar de modo justo e ético as singularidades desde a formação, passando pela organização do mundo do trabalho, formatação e implementação da política pública.

\section{CONSIDERAÇÕES FINAIS}

Diante da discussão que estamos realizando, apoiada nas bases funcionais da Educação do Campo, no diálogo com colaboradores(as) da pesquisa, e com os documentos referenciados, consideramos, finalmente, que o modo como vem se processando a composição do quadro de docentes das EFAs, a exemplo do que evidenciou a realidade da EFA Soinho, põe obstáculos decisivos na realização do PPP da Educação do Campo e da Pedagogia da Alternância.

Contraria o que, de modo geral, ocorre na organização escolar que conhecemos, em que estudantes têm presenças transitórias, em razão do tráfego pelas séries e níveis, enquanto professores e professoras são permanentes, inclusive, devido às responsabilidades que lhes são atribuídas no tocante à construção do ato educativo que exige processualidade, postura investigativa, aprendizado com os erros, dentre outros fatores que compõem a profissionalidade docente. 
Diante disso, para não haja o desperdício da experiência de formação pela alternância conduzida pelas EFAs, reconhecidamente positiva e contribuidora para a superação da exclusão escolar no meio rural, é necessário que a SEDUC/PI reveja o modo de prover o quadro de docentes das mesmas, sem prejuízo à autonomia que a metodologia da alternância exige para (re)fazer-se. Pois, continuando do modo como vem se realizando, o esforço realizado pela escola será permanentemente exaurido a cada final de semestre letivo, quando findam os contratos, mudam as equipes e as energias que poderiam ser direcionadas aos desafios suscitados no processo de formação, se esvaem, parte na burocracia que implica a realização de nova seleção, outra parte nos ajustes para colocar em andamento o trabalho docente.

E, como não é justo esperar que nessa rotatividade, um(a) professor(a) recém chegado(a), possa assumir com qualidade as tarefas impressas no PPP da Educação do Campo e das EFAs, quando, a exemplo da maioria, vem de uma formação básica e superior orientada pelos valores urbanos, que neglicenciam conteúdos e práticas do meio rural e desestimulam às pessoas em formação à conhecer, compreender e valorizar a vida camponesa. Nos resta reafirmar: Educação do Campo é direito do povo do campo!

\section{REFERÊNCIAS}

ARROYO, Miguel Gonzalez. Prefácio. In: KOLLING, Edgar Jorge; NERY, Israel; MOLINA, Mônica Castagna (Orgs.). Por uma Educação Básica do Campo. Brasília, DF: UnB, 1999.

ARROYO, Miguel Gonzalez; FERNANDES, Bernardo Mançano. A educação básica e o movimento social do campo. In: Articulação Nacional Por uma Educação Básica do Campo. Brasília, 1999. Coleção Por uma Educação do Campo, no 2.

BEGNAMI, João Batista. Pedagogia da Alternância como sistema educativo. Revista da Formação por Alternância, Brasília: UNEFAB, n. 3. p. 24-47, 2004.

BEISIEGEL, Celso de Rui. Estado e educação popular: um estudo sobre a educação de adultos. São Paulo: Pioneira, 1974.

BRASIL. Lei no 8.745, de 9 de dezembro de 1993. Dispõe sobre a contratação por tempo determinado para atender a necessidade temporária de excepcional interesse público, nos termos do inciso IX do art. 37 da Constituição Federal, e dá outras providências. Diário Oficial da União, Brasília, DF, 10 dez. 1993.

BRASIL. Lei n. 9.394, de 20 de dezembro de 1996. Lei de Diretrizes e Bases da Educação Nacional. Estabelece as Diretrizes e Bases da Educação Nacional. Diário Oficial da União, Brasília, DF, 24 dez. 1996. Disponível em: < http://portal.mec.gov.br/seed/arquivos/pdf/tvescola/leis/lein9394.pdf >. Acesso em: 27 out. 2019. 
BRASIL. Conselho Nacional de Educação (CNE). Resolução CNE/CEB n. ${ }^{\circ}$ 1, de 3 de abril de 2002 - Institui Diretrizes Operacionais para a Educação Básica nas Escolas do Campo. Diário Oficial da União, Brasília, 9 de abril de 2002. Seção 1, p. 32.

BRASIL. Conselho Nacional de Educação (CNE). Resolução CNE/CEB n ${ }^{\circ}$ 2, de 28 de abril de 2008 - Estabelece diretrizes complementares, normas e princípios para o desenvolvimento de políticas públicas de atendimento da Educação Básica do Campo. Diário Oficial da União, Brasília, 29 de abril de 2008, Seção 1, p. 25.

BRASIL. Ministério da Educação. Censo escolar da Educação Básica 2018: Caderno de instruções. Brasilia, DF, jun. 2018.

CALDART, Roseli Salete. Pedagogia do Movimento Sem Terra: escola é mais do que escola. Petrópolis: Vozes, 2000.

CERQUEIRA, Marcia Cristina de Almeida; SANTOS, Célia Regina Batista dos. As escolas famílias agrícolas, a pedagogia da alternância e o caderno da realidade. In: I Seminário Internacional e I Fórum de Educação do Campo da Região Sul do RS: Campo e Cidade em busca de Caminhos Comuns, Anais eletrônicos... Pelotas: Universidade Federal de Pelotas, 2012. v. 01. p. 01-15. Disponível em: <

http://coral.ufsm.br/sifedocregional/images/Anais/Eixo $\% 2004 /$ Marcia $\% 20$ Cristina $\% 20 \mathrm{de} \% 20$ A. $\% 20$ Cerqueira $\% 20 \mathrm{e} \% 20 \mathrm{C} \% \mathrm{C} 3 \%$ A 9 lia $\% 20$ Regina $\% 20 \mathrm{~B} . \% 20 \mathrm{dos} \% 20$ Santos.pdf $>$. Acesso em: 11 ago. 2019.

CUT. A prática política e pedagógica da CUT no Nordeste: um diálogo com as experiências. Recife: Edições Bagaço, 2000.

FREIRE. Paulo. Educação e mudança. Rio de Janeiro: Paz e Terra, 1983.

FREIRE, Paulo. Pedagogia do oprimido. Rio de Janeiro: Paz e Terra, 2005.

GERHARDT, Tatiana Engel; SILVEIRA, Denise Tolfo. Métodos de pesquisa. Porto Alegre: UFRGS, 2009.

GIMONET, Jean-Claude. Pedagogia da Alternância. Petrópolis: Vozes, 1999.

GIMONET, Jean-Claude. Praticar e compreender a Pedagogia da Alternância dos CEFFAS. Petrópolis: Vozes, 2007.

JESUS, José Novais. Escola Família Agrícola: uma proposta de educação em desenvolvimento no campo e do campo. In: QUEIROZ, João Batista Pereira de; SILVA, Virgínia Costa e; PACHECO, Zuleika (Orgs.). Pedagogia da Alternância: construindo a educação do campo. Goiânia. Editora da UCG; Brasília: Editora Universa, 2006. p. 07-158.

JESUS, Janinha Gerke de. Formação de professores na pedagogia da alternância: saberes e fazeres do campo. Vitória: GM, 2011.

KOLLING, Edgar Jorge; NERY, Israel; MOLINA, Mônica Castagna (Orgs.). Por uma Educação Básica do Campo. Brasília: UnB, 1999. 
KOLLING, Edgar Jorge; CERIOLI, Paulo Ricardo; CALDART, Roseli Salete (Orgs.).

Educação do Campo: identidade e políticas públicas. Brasília: Articulação Nacional por uma Educação do Campo, 2002. Coleção Por uma Educação do Campo, no 4.

LIMA, Maria Raquel Barros; SOUSA, Luana Vieira de; MELO, Patricia Sara Lopes. Pedagogia da Alternância em Escolas Famílias Agrícolas (EFAS) do Piauí: plano de estudos enquanto mediação da prática educativa. In: III Congresso Ibero-Americano de Humanidades, Ciências e Educação, Anais eletrônicos... Criciúma, Universidade do Extremo Sul Catarinense, 2018, p. 31-42.

MANFREDI, Silvia Maria. Educação sindical entre o conformismo e a crítica. São Paulo: Loyola, 1986.

MARCONI, Marina de Andrade; LAKATOS, Eva Maria. Metodologia científica. 5. ed. São Paulo: Atlas, 2011.

MINAYO, Maria Cecília de Souza (Org.). Pesquisa social: teoria, método e criatividade. 18. ed. Petrópolis: Vozes, 2001.

NOSELLA, Paolo. Uma nova educação para o meio rural: sistematização e problematização da experiência educacional das Escolas da Família Agrícola do Movimento de Educação Promocional do Espírito Santo. 1977. 204 f. Dissertação (Mestrado em Filosofia da Educação) Pontifícia Universidade Católica de São Paulo, São Paulo, 1977.

PRODANOV, Cleber; FREITAS, Ernani. Metodologia do trabalho científico: métodos e técnicas da pesquisa e do trabalho acadêmico. 2. ed. Novo Hamburgo: Feevale, 2013.

PIAUÍ. Decreto no 15.547, de 12 de março de 2014 - Regulamenta a Lei estadual n. 5.309, de 17 de julho de 2003, que dispõe sobre a contratação por tempo determinado no serviço para atender a necessidade temporária de excepcional interesse público na Administração Estadual direta, nas autarquias e fundações públicas, sob o regime de direito administrativo, nos termos do artigo 37, inciso IX, da Constituição Federal. Teresina (PI). Diário Oficial do Estado, no 47, p. 05-11, de 12 mar. 2014.

RUIZ, João Álvario. Metodologia científica: guia para eficiência nos estudos. São Paulo: Atlas, 2008.

SANTOS, Boaventura de Sousa. Por uma concepção multicultural de direitos humanos. Lua Nova, São Paulo, n. 48, p. 11-32, jun., 1997.

TRIVIÑOS, Augusto Nibaldo Silva. Introdução à pesquisa em Ciências Sociais: a pesquisa qualitativa em educação.São Paulo: Atlas, 2008. 